\title{
Psychological aspects of ensuring the efficiency of professional activity of a project engineers
}

\author{
Olena Khokhlina ${ }^{1}$, Lubov Pomytkina ${ }^{1, *}$, Lada Yakovytska $^{1}$, Oksana Lych $^{1}$, and Denys \\ Khokhlin ${ }^{2}$ \\ ${ }^{1}$ National Aviation University, ave. Liubomyra Huzara 1, 03058, Kyiv, Ukraine \\ ${ }^{2}$ Kyiv National University of Construction and Architecture, ave. Povitroflotskyy, 31, 03037, \\ Kyiv, Ukraine
}

\begin{abstract}
The article presents the results of theoretical and empirical research of the problem of psychological aspects of ensuring the efficiency of professional activity of a Project Engineers in the context of the theory of general and special abilities, the need to take into account the general and individual-typological in the mental development of the subject of labor. The importance of considering professional skills in connection with the intellectual readiness of the subject to the activity and individual style of its implementation is theoretically substantiated. The empirical study revealed the presence of correlations between the efficiency of professional activity, psychological readiness and individual style of activity. The most referent in the description of the professional skills of project engineers are the time of labor tasks performance and individual style of activity, and the organizing factor in the unity of these indicators is the generalization of mental activity, which forms the core of intellectual readiness for work. Correlation analysis of the data allowed us to identify the presence of clear links between: 1) the efficiency of activity by time indicator and ISA: the more ISA corresponds to the reference method, the less time is spent on solving the labor task, and vice versa; 2) between ISA and intellectual readiness for activity; the higher the level of complexity of labor tasks, the higher the level of correlation between these phenomena.
\end{abstract}

\section{Introduction}

The importance of researching the problem is due not only to the need to obtain high performance indicators of workers, but also the fact that the efficiency of activities associated with a positive attitude to it, are considered in psychology as necessary conditions and evidence of personality growth of a human, self-realization, adaptability to life activities. Ensuring the efficiency of professional activity involves the study of psychological aspects of this process.

\footnotetext{
* Corresponding author: Lyubvit@bigmir.net
} 
The success of work is determined by the presence of the specialist's necessary knowledge and methods of action (skills and abilities) to perform labor tasks, and the level of development of his general and individual-typological mental properties that meet the requirements of labor activity. The intellectual readiness of the employee for activity was defined as the general property, as individual style of activity - individual-typological property.

Thus, in the context of global intellectualization of labor in all spheres of production, special attention is paid to psychological, namely, intellectual readiness for activity - the readiness of the mental sphere of the subject to perform it (Herrera, \& Barrientos; Micallef, Huet, \& Kayyali; Nagovitsyn et al.; Petrova, \& Kozlova) [1-4]. We concretize the mental sphere in the context of the theory of activity, general labor and special (professional) training (Molyako, Synov, Khokhlina, Pomytkina, Pomytkin, etc.) [5], the theory of general and special abilities of the personality, thinking and mental development in general (Kalmykova, Kostyuk, Krutetsky, Levitov, Laytes, Menchinskaya, Raev, Rubinstein, Slavskaya, etc.) and consider as a system of qualities of mental activity, from the formation of which depends the ability to effectively solve labor problems. The formation of mental qualities is the result of the development of thinking as the pinnacle in providing the mind with a cognitive mental process. The purpose of thinking is to pre-determine the method of activity based on the ability to generalize. Generalization of thinking (and mind) is a key mental formation of intellectual readiness for work, the essence of which is the focus of thinking on the selection of the essential, and an indicator is the ability to determine the optimal way of working.

Individual style of activity is considered in the context of the problem of human adaptation with its individual-typological, and first of all temperamental, features for activity, ensuring efficiency of its assimilation and performance (Klymov; Khokhlina et al.; Luzik, Akmaldinova, \& Tereminko; Pomytkina; Tolochek) [6-8]. Individual style of activity (ISA) is considered as a stable system of methods of activity that provides the best performance by a person and characterizes it in typical conditions; it is an individualpeculiar system of psychological means to which a person consciously or spontaneously resorts to balance own typologically conditioned individuality with objective, external working conditions (Pakhmutova et al.; Ponomarenko, Krylov, \& Somova; Topuzov, Malykhin, \& Yarmolchuk) [9-11]. That is a compensatory meaning of ISA for effective performance of activity; and the essence of the use of the compensation mechanism is that due to ISA the "weaknesses" of person's development and activity are leveled, and the positive ones are used as much as possible; thus the activity is performed in a "convenient" way, and the person at the same time feels a state of comfort. The ISA is based on the individual method, which is determined on the basis of comparison with the reference normatively approved, i.e. generalized and fixed in the instructions designed for the abstract subject and the average conditions (Khokhlina).

Goal - coverage of the results of theoretical and empirical research of the problem of psychological aspects of ensuring the efficiency of labor activity of a project engineers, namely the formation of his intellectual readiness to perform work and individual style of activity.

The hypothesis of the study is that the efficiency of the professional activity of the subject is associated with the formation of his intellectual readiness for work and individual style of activity.

\section{Methods}

Theoretical and empirical methods of psychological research are used, including observation of the process and results of work, survey, method of expert evaluation, method 
of studying documentation, experiment using a system of specially designed labor tasks of professional content to study the formation of thinking, generalization of the mind, individual style and efficiency of professional activity, hardware technique "support Mede», proofreading (using proofreading form Bourdon), methods of studying spatial thinking by I. Yakimanska, as well as procedures for qualitative and quantitative processing. The research work covered 33 project engineers.

\section{Results}

At the empirical stage of the study, the most important mental professionally significant functions were studied - attention, sensorimotor coordination, thinking (technical, spatial), generalization of mental activity as a core of intellectual readiness, individual style of activity and efficiency of professional activity by indicators of quality (correctness and completeness) and time spent on performing the labor tasks. The obtained data on the manifestation of defined phenomena were subject to correlation analysis, due to which the most "sensitive" to professional skills psychological factors were clarified. Significant correlations between the studied phenomena are presented in Table 1.

The results of in-depth analysis of the data obtained in the study and the identified correlations allowed us to state the following.

1. The ability to distribute attention does not affect the quality of professional tasks. It is related to time and method of work: the higher the level of ability to distribute attention by the indicator of productivity (stability), the less time it takes to complete the task, and vice versa $\left(\rho^{\mathrm{s}}=-0.37^{6}\right)$. Improving the accuracy of attention distribution slightly increases the time spent on work $\left(\rho^{\mathrm{s}}=0.11\right)$. The ability to distribute attention by accuracy indicator has a low degree of inverse correlation with the individual mode of operation $\left(\rho^{\mathrm{s}}=-0.21\right)$ : the greater the accuracy of the distribution of attention, the more the method of work of a professional deviates from the reference, and vice versa.

Table 1. Correlations between mental functions, individual style of activity, efficiency of activity.

\begin{tabular}{|c|c|c|c|c|}
\hline \multirow{2}{*}{\multicolumn{2}{|c|}{ Mental functions }} & \multicolumn{2}{|c|}{ Efficiency of activity } & \multirow{3}{*}{$\begin{array}{l}\text { Individual style of } \\
\text { activity (level of } \\
\text { compliance with the } \\
\text { reference method) }\end{array}$} \\
\hline & & Quality & Time & \\
\hline \multirow[t]{2}{*}{$\begin{array}{l}\text { Attention } \\
\text { (distribution) }\end{array}$} & $\begin{array}{l}\text { Productivity } \\
\text { (stability) }\end{array}$ & & $-0.37^{6}$ & \\
\hline & Accuracy & & & -0.21 \\
\hline \multicolumn{2}{|c|}{ Sensorimotor coordination (level) } & & -0.21 & \\
\hline \multirow{2}{*}{$\begin{array}{l}\text { Intellectual } \\
\text { readiness }\end{array}$} & Thinking & & $-0.45^{5}$ & \\
\hline & $\begin{array}{l}\text { Generalization } \quad \text { of } \\
\text { mental activity }\end{array}$ & 0.20 & $-0.53^{4}$ & $0.54^{4}$ \\
\hline \multicolumn{2}{|c|}{$\begin{array}{l}\text { Individual style of activity (level of } \\
\text { compliance with the reference method }\end{array}$} & & $-0.47^{5}$ & \\
\hline
\end{tabular}

2. Sensorimotor coordination of the subjects does not affect the quality and method of work, but is associated with a low level of correlation with the speed of tasks performance $\left(\rho^{\mathrm{s}}=-0.21\right)$.

3. The level of technical thinking does not affect the qualitative indicators of labor efficiency. A clear feedback between the level of formation of technical thinking and professional skill can be traced only by the time indicator $\left(\rho^{\mathrm{s}}=-0.45^{5}\right)$. The same level and 
nature of the correlation was found between the generalization of mental activity, which is the core quality of intellectual readiness for work, and the time of labor tasks performance $\left(\rho^{\mathrm{s}}=-0.53^{4}\right)$. Thus, the formation of thinking and generalization of mental activity contributes to faster performance.

The generalization of the mind is insignificant, but it is related to the quality of labor tasks $\left(\rho^{\mathrm{s}}=0.20\right)$.

A clear level of correlation was also found between the generalization of the mind and $\operatorname{ISA}\left(\rho^{\mathrm{s}}=0.54^{4}\right)$.

4. There is no connection between the quality and time of professional tasks performance, as indicators of efficiency of activity; no connection was found between the quality and style (method) of work. The study showed a clear feedback between professional skills by time indicator, on the one hand, and individual style of activity (its compliance with the reference method of work), on the other $\left(\rho^{\mathrm{s}}=-0.47^{5}\right)$. That is, with the reduction of time spent on the task, the deviation of the subject from the reference method of work decreases, and vice versa.

5. Among the indicators of professional efficiency time is more referent than the quality (correctness) of labor tasks performance $\left(\rho^{\mathrm{s}}=0.36^{6}-0.41^{5}\right)$. The reference indicator of professional skill is also an individual style of activity $\left(\rho^{\mathrm{s}}=0.41^{5}-0.61^{2}\right)$. The organizing factor in the unity of these indicators is the generalization of mental activity, which forms the core of intellectual readiness for activity.

\section{Discussion}

The results of the conducted study showed that individuals differ from each other not only in the final results of activities, but also in ways to achieve these results (i.e. ISA) Maslakov, et al.; Sergeeva, et al.; Sokurenko, Shvets, \& Uvarov; Voloshenko, Dzhezhik, \& Azarkina [12-14], which require correction and formation in accordance with individual typological properties and labor requirements.

To achieve high results in performance of a professional, it is important to form a psychological, namely intellectual readiness for work - those mental qualities that ensure the successful completion of labor tasks. For the completeness of the study of intellectual readiness in the subsequent stages of the study, we solved the problem of determining other components, the manifestation of which will contribute to the generalizing activity of the employee's thinking in the process of choosing the optimal way of working and performing production tasks.

\section{Conclusions}

The results of the study showed the presence of correlations between the efficiency of the professional activities of project engineers, psychological readiness for activity and individual style of work. The most reference indicators in the description of their professional skills are the time of labor tasks performance and individual style of activity, and the organizing factor in the unity of these indicators is the generalization of mental activity, which forms the core of intellectual readiness for activity.

Correlation analysis of the data allowed us to identify the presence of clear correlation between:

- efficiency of activity by time indicator and ISA: the more ISA corresponds to the reference method, the less time is spent on solving the labor task, and vice versa; between the efficiency of activity by time indicator and intellectual readiness for activity, namely the generalization of the mind; 
- individual style of activity and intellectual readiness for activity; the higher the level of complexity of labor tasks, the higher the level of communication between these phenomena.

Thus, the results of theoretical and empirical research prove that to achieve high efficiency indicators of the subject's professional activity it is important to increase the level of intellectual readiness for work and the formation of individual style of activity, which provides the highest level of adaptation to individual properties to the conditions of performing activity.

\section{References}

1. I.M. Herrera, C.C. Barrientos, Revista Inclusions, 6, 48-61 (2019)

2. R. Micallef, I. Huet, R. Kayyali, Pharmacy Education, 20(1), 103-115 (2020)

3. R.S. Nagovitsyn, A.Y. Osipov, M.D. Kudryavtsev, et al., Amazonia Investiga, 9(26), 341-348 (2020)

4. V.N. Petrova, N.V. Kozlova, Sibirskiy psikhologicheskiy Zhurnal - Siberian Journal of Psychology, 70, 59-74 (2018) doi: 10.17223/17267080/70/5

5. V.M. Synov, O.P. Khokhlina, Aktualni pytannia korektsiinoi osvity, 16(1), 230-245 (2020) doi: 10.32626/2413-2578.2020-16.230-244

6. O. Khokhlina, L. Pomytkina, O. Lych, et al., Psychological determinacy of communication styles of aviation industry students. VIII International Scientific Conference Transport of Siberia. IOP Conference Series: Materials Science and Engineering, 918 (Novosibirsk, 2020) doi:10.1088/1757-899X/918/1/012175

7. E. Luzik, O. Akmaldinova, L. Tereminko, Advanced Education, 13, 103-111 (2019) doi: $10.20535 / 2410-8286.185230$

8. V. Tolochek, Psikhologicheskii zhurnal, 40(4), 57-72 (2019) doi: 10.31857/S020595920005470-3

9. M. Pakhmutova, S. Bakhtina, S. Andreeva, T. Golovanova, 4th International Conference on Education 2017, 400-404 (Dubai, 2017)

10. E. Ponomarenko, E. Krylov, K. Somova, $14^{\text {th }}$ International Technology, Education and development conference (Inted 2020), 7744-7748 (Valencia, 2020)

11. O.M. Topuzov, O.V. Malykhin, T.M. Yarmolchuk, Information Technologies and Learning Tools, 77(3), 205-222 (2020) doi: 10.33407/itlt.v77i3.3351

12. M.G. Sergeeva, A.V. Serebrennikova, N.G. Bondarenko, et al., Amazonia Investiga, 8(18), 425-431 (2019)

13. V. Sokurenko, D. Shvets, V. Uvarov, Science and Education, 3, 85-91 (2018) doi: 10.24195/2414-4665-2018-3-11 